\title{
Modified Toe Amputation Reduces Hematoma Rate in Diabetic Foot Ulcer
}

\author{
Sooseong Leem, Jung Woo Chang, M. Seung Suk Choi \\ Department of Plastic and Reconstructive Surgery, Hanyang University Guri Hospital, Guri, Korea
}

\begin{abstract}
Background: One of the common methods to perform toe amputation is the enucleation of the toe at the metatarsophalangeal joint. The level of the web space skin is far more distal than the amputation level; hence, a dead space is inevitably formed between the level of skin closure and the metatarsophalangeal joint, which is prone to hematoma formation. We describe a method to amputate the toe at the proximal phalanx, just proximal to the web space skin, that prevents dead space formation and potentially reduces the hematoma rate.

Methods: Eleven patients with diabetic foot ulcers had a toe amputation just proximal to the level of the web space skin. After creation of a small flap for closure, the proximal phalanx was amputated approximately 2-3 mm proximal to the level of the web space skin. The skin flap was closed in a primary or delayed fashion depending on the infection status. Two patients underwent the operation without discontinuing anti-platelet medication. Follow-up loss occurred in one case.

Results: None of the patients showed hematoma formation. One patient underwent additional amputation due to residual infection. All the other patients healed primarily without any additional revision or surgery of the amputated toe.

Conclusion: The described toe amputation technique at the level of the web space skin prevents dead space formation, which can occur after toe enucleation at the metatarsophalangeal joint, thus inhibits hematoma formation.
\end{abstract}

Keywords: Diabetic foot, Amputation, Toes, Hematoma

\section{Introduction}

More than 422 million patients worldwide suffer from diabetes mellitus and its complications [1]. Annually, 4.9 million deaths are caused by diabetes mellitus. One of the most common, but severe and expensive, complications of diabetes is diabetic foot ulcer (DFU). Patients with diabetes have a 10 to 20 times higher chance of undergoing limb amputation than non-diabetic individuals [2]. In a large cohort study, about $15 \%$ of the patients with diabetes required amputation [3].

One of the common methods of amputation in patients with diabetes is toe amputation at the metatarsophalangeal joint. When amputating the toe at the metatarsophalangeal joint, one has to consider that the level of the web space skin is far more distal than the metatarsophalangeal joint. The distance from the level of the web space skin to the actual amputation line encloses a large dead space, which can lead to hematoma formation. Moreover, the dead space created by amputation of a toe alters the biomechanics which can cause complications such as re-ulceration, or deviation deformities of other toes, thereby leading to an increased risk of amputation of the other toes [4].

Toe amputation is a relatively frequently performed procedure in DFU patients, but there are only few studies discussing the surgical methods. We describe a method to amputate the toe at the proximal phalanx to prevent dead space formation in order to

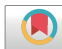

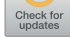 \\ Original Article \\ Received: July 11, 2018 \\ Revised: August 8, 2018 \\ Accepted: August 9, 2018 \\ Corresponding author: \\ Matthew Seung Suk Choi, M.D. \\ Department of Plastic and Reconstructive Surgery, Hanyang University Guri Hospital, 153 Gyungchun-ro, Guri 11923, Korea \\ Tel: +82-31-560-2334 \\ Fax: +82-31-560-2338 \\ E-mail: msschoi1@gmail.com}

This is an Open Access article distributed under the terms of the Creative Commons Attribution Non-Commercial License (http://creativecommons.org/licenses/by-nc/4.0/) which permits unrestricted non-commercial use, distribution, and reproduction in any medium, provided the original work is properly cited.

(c) 2018 Korean Wound Management Society 
reduce hematoma rate and avoid deviational deformities of the remaining toes.

\section{Methods}

In a retrospective study, patients undergoing toe amputation from March 2016 to January 2018 at our department were identified. Of the 67 patients with toe amputation, patients with toe amputation at sites other than the proximal phalanx and patients who did not have diabetes were excluded. Eleven patients with toe amputation at the level of the web space skin for DFU were included in the study and reviewed (Table 1). Cases with hematoma, wound problems requiring revision or more proximal amputation, and wound infection were recorded.

\section{Surgical Technique}

The incision was designed in a fish mouth shape or as a dorsal or plantar skin flap depending on where the more reliable skin flap was located. After the skin incision, bony resection of the proximal phalanx was carried out with an oscillating saw about $2-3 \mathrm{~mm}$ proximal to the web space skin (Fig. 1). If signs of osteomyelitis were encountered while cutting the bone, the proximal phalanx was trimmed more proximally. The following signs were interpreted as osteomyelitic: reduced resistance during the sawing procedure, lack of bone bleeding, or purulent secretion from cancellous bone. A rongeur was used to trim the osteomyelitic bone until hard bone was felt and bone bleeding was encountered. The skin flaps were trimmed such as they did not cause any tension, which could eventually cause skin necrosis, and were not too loose, which could cause hematoma formation. In the absence of infection, the wound was closed primarily after insertion of a Penrose drain. Infected wounds were left open for further treatment and closed secondarily, after they were deemed clean. A short leg splint was applied in all cases.

The drain was removed 1-4 days after operation depending

Table 1. Patient information

\begin{tabular}{|c|c|c|c|c|c|c|c|c|}
\hline Patient No. & Sex/Age & $\begin{array}{l}\text { Underlying } \\
\text { disease }\end{array}$ & $\begin{array}{l}\text { Amputated } \\
\text { Toe }\end{array}$ & $\begin{array}{l}\text { Preop-an } \\
\text { gioplasty }\end{array}$ & $\begin{array}{l}\text { Antiplatelet } \\
\text { drug }\end{array}$ & Follow up & Result & $\begin{array}{l}\text { Postoperative } \\
\text { state }\end{array}$ \\
\hline 1 & $\mathrm{M} / 48$ & DM/HTN & $2 n d$ & $\mathrm{~N}$ & $\mathrm{~N}$ & $2 m$ & $\begin{array}{l}\text { No hematoma } \\
\text { No deviation of other toes } \\
\text { Wound infection }\end{array}$ & Additional amputation \\
\hline 2 & $F / 61$ & DM/HTN & 4th & $\mathrm{N}$ & $\mathrm{N}$ & 1 y $6 \mathrm{~m}$ & $\begin{array}{l}\text { No hematoma } \\
\text { No deviation of other toes }\end{array}$ & $\begin{array}{l}\text { Primary healing } \\
\text { Amputation of another toe }\end{array}$ \\
\hline 3 & $\mathrm{M} / 50$ & DM/HTN/CKD & 4th & $\mathrm{N}$ & $\mathrm{N}$ & 1 y $5 \mathrm{~m}$ & $\begin{array}{l}\text { No hematoma } \\
\text { No deviation of other toes }\end{array}$ & Primary healing \\
\hline 4 & $\mathrm{M} / 52$ & DM & 5th & $\mathrm{N}$ & $\mathrm{N}$ & $22 d$ & $\begin{array}{l}\text { No hematoma } \\
\text { No deviation of other toes }\end{array}$ & Primary healing \\
\hline 5 & $F / 54$ & DM & 4th, 5th & $\mathrm{N}$ & $\mathrm{N}$ & $2 m$ & $\begin{array}{l}\text { No hematoma } \\
\text { No deviation of other toes }\end{array}$ & Primary healing \\
\hline 6 & $\mathrm{M} / 69$ & DM & 2nd & $Y$ & $\begin{array}{l}\text { Aspirin } \\
\text { Clopidogrel } \\
\text { Cilostazol }\end{array}$ & $3 m$ & $\begin{array}{l}\text { No hematoma } \\
\text { No deviation of other toes }\end{array}$ & Primary healing \\
\hline 7 & $\mathrm{~F} / 70$ & DM/HTN/CKD & 2nd & $Y$ & $\begin{array}{l}\text { Aspirin } \\
\text { Clopidogrel } \\
\text { Cilostazol }\end{array}$ & $1 \mathrm{y}$ & $\begin{array}{l}\text { No hematoma } \\
\text { No deviation of other toes }\end{array}$ & Primary healing \\
\hline 8 & $\mathrm{M} / 64$ & DM/HTN & 2nd & $\mathrm{N}$ & $\mathrm{N}$ & $1 \mathrm{y}$ & $\begin{array}{l}\text { No hematoma } \\
\text { No deviation of other toes }\end{array}$ & Primary healing \\
\hline 9 & $\mathrm{M} / 59$ & $\mathrm{DM} / \mathrm{CKD}$ & $3 \mathrm{rd}$ & $\mathrm{N}$ & $\mathrm{N}$ & $2 m$ & $\begin{array}{l}\text { No hematoma } \\
\text { No deviation of other toes }\end{array}$ & $\begin{array}{l}\text { Primary healing } \\
\text { Amputation of another toe }\end{array}$ \\
\hline 10 & $\mathrm{M} / 52$ & DM & 4th & $\mathrm{N}$ & $\mathrm{N}$ & $3 m$ & $\begin{array}{l}\text { No hematoma } \\
\text { No deviation of other toes }\end{array}$ & Primary healing \\
\hline 11 & $\mathrm{M} / 58$ & $\mathrm{DM}$ & 5 th & $\mathrm{N}$ & $\mathrm{N}$ & $0 \mathrm{~m}$ & $\begin{array}{l}\text { No hematoma } \\
\text { No deviation of other toes }\end{array}$ & Follow up loss \\
\hline
\end{tabular}

DM, diabetes mellitus; HTN, hypertension; CKD, chronic kidney disease. 

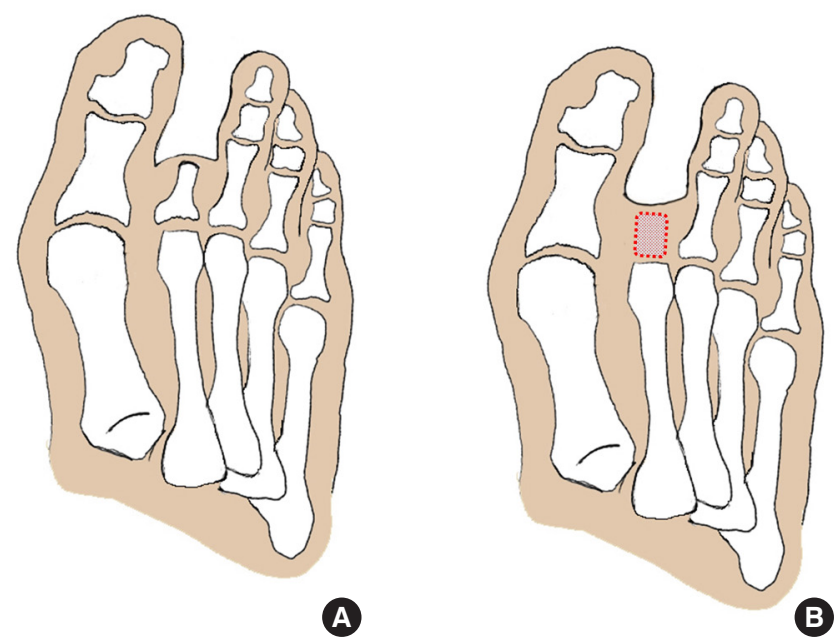

Fig. 1. Comparative image of modified and conventional toe amputation. Images of modified toe amputation (A) and conventional toe enucleation at the metatarsophalangeal joint level (B). The bony resection of the proximal phalanx is carried out at 2-3 $\mathrm{mm}$ proximal to the skin web space level in modified toe amputation (A). The potential dead space in metatarsophalangeal enucleation is shown as the red dotted space (B).

on the amount of bleeding through the drain. Stitches were removed approximately 14 to 21 days after operation depending on wound status.

\section{Results}

A total of 11 patients with diabetic foot underwent toe amputation at the level of the web space skin. All patients had type 2 diabetes. Patient characteristics and results are shown in Table 1. Eight patients were male and three were female. Their mean age was 57.9 years, ranging from 48 to 70 years. One patient was lost to follow-up due to self-discharge. The mean followup was 6.5 months, ranging from $0-18$ months. Two patients (18.2\%) had undergone percutaneous transluminal angioplasty prior to the surgery, and were on antiplatelet medication at the time of the amputation. In five patients (45.5\%), diabetes mellitus was accompanied by hypertension. Three patients (27.3\%) had chronic kidney disease. There was no case of hematoma formation. One patient required additional amputation to remove the proximal phalanx stump due to residual infection. Two patients required amputation of an additional toe. Except for one case, in which additional amputation of the remaining proximal phalanx was required, no major wound complications, such as wound necrosis or wound infection were seen.

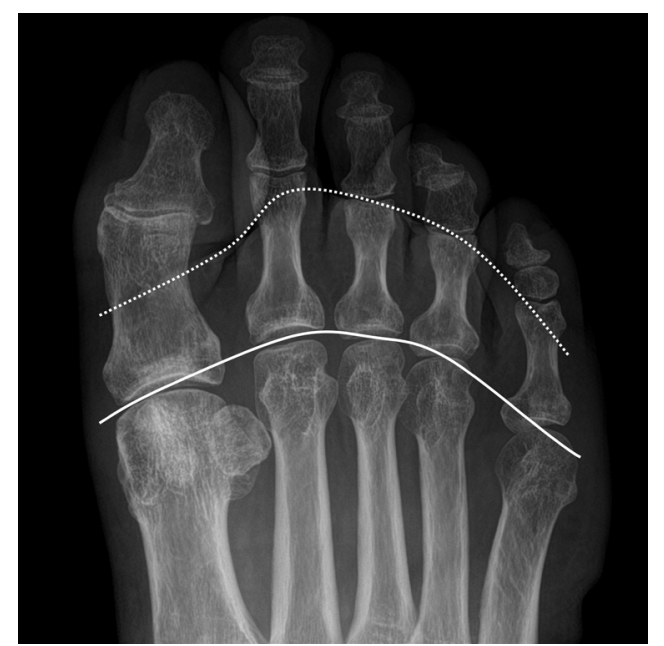

Fig. 2. Discrepancy between web space skin and metatarsophalangeal joint. Plain X-ray of the foot of a 53-year-old male with diabetes mellitus. The top of the web space skin line (dotted line) is far more distal than the metatarsophalangeal joint line (solid line). Enucleation at metatarsophalangeal joint and skin closure at the web space skin line will result in a dead space, which will increase hematoma formation.

\section{Discussion}

Treatment of DFU is challenging, since it is associated with morbidity, disability, and decrease in the quality of life [5]. According to a European study, nearly $60 \%$ of DFU cases are complicated by infection [6]. Infected DFU accompanied by osteomyelitis is associated with a high risk of amputation [7]. If the level of amputation is misjudged, osteomyelitis can persist, and infection becomes very difficult to control. Such a case may even require an additional amputation. Therefore, when deciding on the level of amputation, assessment of the presence and extent of osteomyelitis is the first point to be considered. Skin and soft tissue cover for the wound is the next factor. As peripheral vascular disease is almost always present in DFU patients, amputation at a too distal level would cause wound healing problems. Amputation at too far a proximal level, however, would cause unnecessary functional deficits.

The discrepancy in the anatomic position between the web space skin of the foot and the metatarsophalangeal joint is greater than usually perceived (Fig. 2). When the toe is amputated at the metatarsophalangeal joint, this distance inevitably results in a dead space, which is prone to hematoma formation. Development of a hematoma often results in a secondary infection or delay in wound healing [8-10]. This dead space 

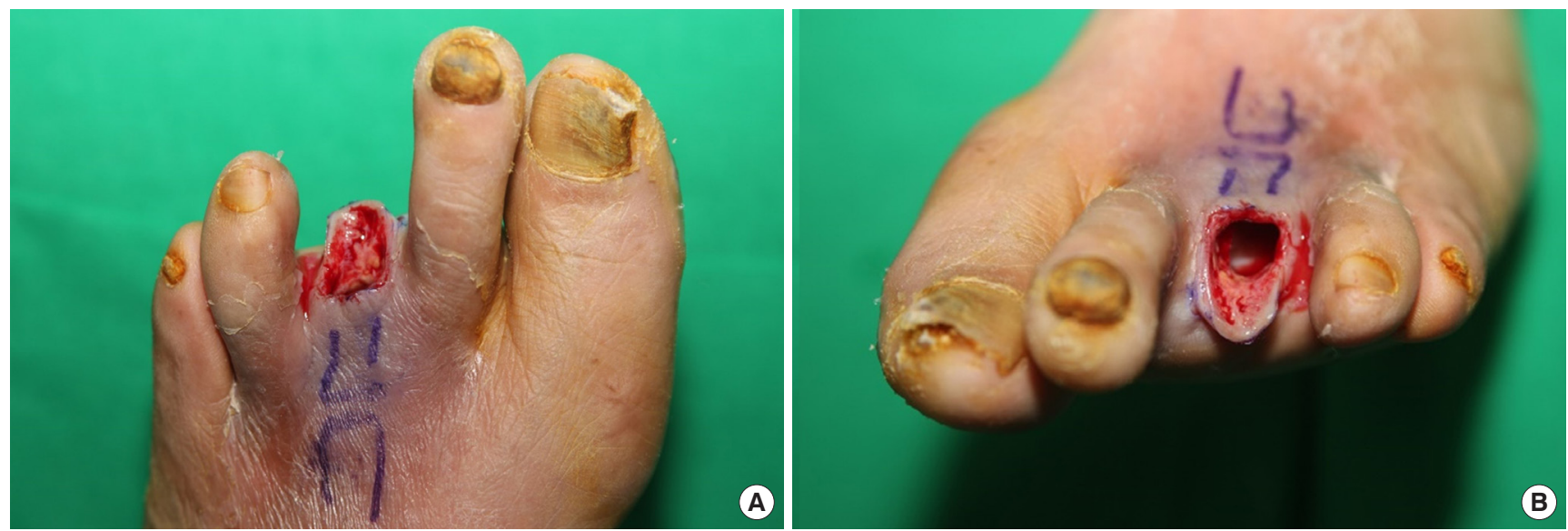

Fig. 3. Dead space after a toe enucleation. Photos of a patient with enucleation of the 3rd toe at the metatarsophalangeal joint. A long distance between the level of the web space skin and metatarsophalangeal joint is seen. A narrow longitudinal canal with substantial depth can be seen in the photo.
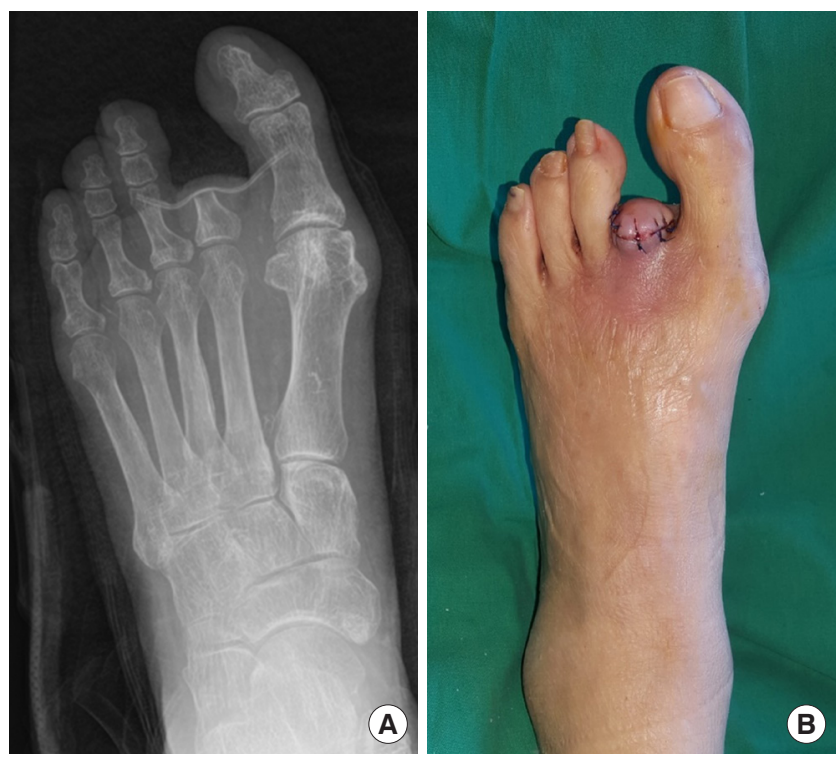

Fig. 4. Postoperative X-ray and photo. Leaving a small proximal phalanx stump obliterates the dead space.

has substantial depth in a narrow canal and the metatarsophalangeal joint is located deep within this canal. Moreover, the axis of the surgical procedure is transverse to the main axis of the canal. Hence, surgeons may face technical difficulties while performing metatarsophalangeal enucleation (Fig. 3).

In general surgical practice, drains are used to avoid hematoma formation. Surgical drains, however, serve as a connection between the inside of the wound and the outside. This, in turn, can lead to an increased rate of infection [11]. In other types of surgery, there are several techniques to obliterate the dead space, such as quilting sutures, use of fibrin sealants and
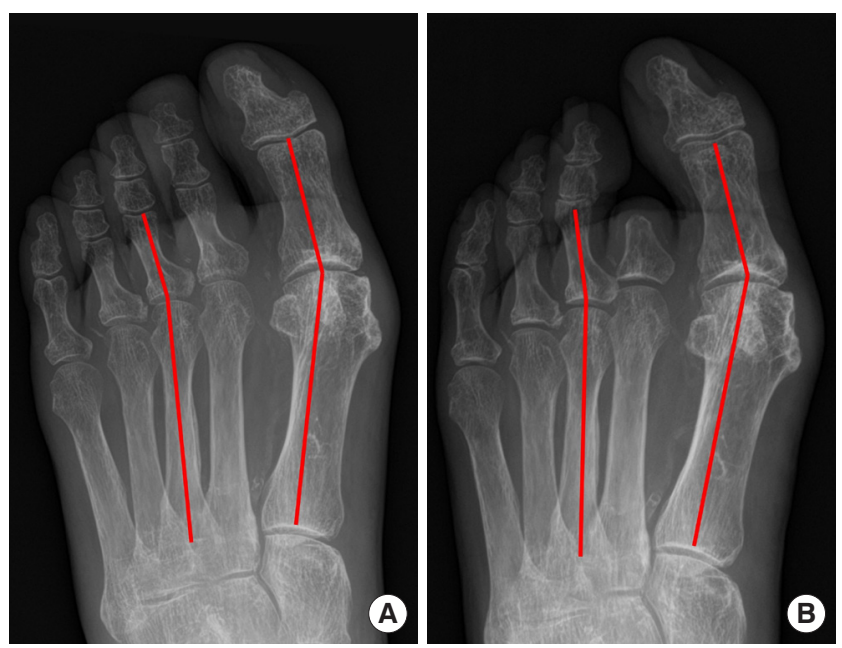

Fig. 5. Preoperative and postoperative $X$-ray comparison. Preoperative $X$-ray $(A)$ and 1 year postoperative $X$-ray $(B)$ after 2 nd toe amputation with the modifed method. The neighboring metatasophalangeal joint showed only minimal deviation to the amputated digit.

sclerotherapy, use of closed suction drains, or compression dressings [12-15]. However, in toe amputations of DFU patients, there are difficulties in applying such methods as they may interfere with blood circulation, which will lead to wound problems necessitating additional surgery or even amputation.

Toe amputation at the level of the web space skin leaves a small proximal phalanx stump, which serves to obliterate the dead space (Fig. 4). This proximal phalanx stump can only be preserved if it is free of infection. Therefore, it is important to assess whether this stump is osteomyelitic. Both preoperative radiographic studies and intraoperative findings must be eval- 
uated. If there is any evidence of remaining osteomyelitis, there should be no hesitation to amputate the toe at a more proximal level to remove all the bone affected by osteomyelitis.

In our study, wound infection remained in one case and further amputation for skin closure was needed. Two patients were taking antiplatelet agents at the time of the amputation, which can potentially increase the risk of hematoma formation. Both patients were taking triple antithrombotic therapy (aspirin, clopidogrel, and cilostazol). However, no hematoma formation was seen in these cases.

In our clinical practice, deviation deformity after toe enucleation at the metatarsophalangeal joint is often observed. This deviation could be rotation of a neighboring toe, a transverse deviation, or a combination of both. Very little information can be found about these sequelae in the literature. In this study, we have not found such a deviation or only minimal deviation of the remaining toes was observed (Fig. 5). Jain et al. [4] suggested that this deviation deformity is caused by biomechanical changes after toe amputation. Loss of the $2 \mathrm{nd}$, 3rd, or 4th toes causes deviation of the neighboring toes due to loss of support, which leads to biomechanical changes. The altered biomechanics may result in re-ulceration or deviation of the remaining toes, and increases the risk of amputation of the other toes and the foot. We hypothesize that, by leaving a stump of the proximal phalanx, these biomechanical changes are lower than those seen with metatarsophalangeal amputation, and postoperative deviation is reduced. None of our patients showed substantial postoperative deviation, but due to the small number of cases and short follow-up period, we are unable to assertively state our hypothesis.

\section{Conclusions}

Due to the acral anatomic position of the toes, their blood perfusion is frequently compromised, which makes toe amputation a relatively common procedure in patients with diabetic foot. We suggest amputation of the toe at the level of the web space skin, if no evidence of osteomyelitis is seen in the proximal phalanx stump. This small procedural difference can prevent dead space formation and reduce the hematoma rate. Moreover, it can also minimize lateral or medial reclination of the neighboring toes as the structural imbalance is less severe than an amputation along the metatarsophalangeal joint line. Due to the limited number of cases, we have not been able to prove our observations statistically. A study including a larger patient pool and comparison with metatarsophalangeal enu- cleation is needed to compare infection rates, hematoma rates, and biomechanical changes.

\section{References}

1. WHO. Global Report on Diabetes. Geneva, 2016.

2. International Diabetes Federation. IDF Diabetes Atlas, 8th ed. Brussels; 2017.

3. Ramsey SD, Newton K, Blough D, et al. Incidence, outcomes, and cost of foot ulcers in patients with diabetes. Diabetes Care 1999;22:382-7.

4. Jain AK, Varma AK, R Mol, et al. Digital Amputations in the Diabetic Foot. J diab foot comp 2010;2:12-7.

5. Carrington AL, Mawdsley SK, Morley M, et al. Psychological status of diabetic people with or without lower limb disability. Diabetes Res Clin Pract 1996;32:19-25.

6. Prompers L, Huijberts M, Apelqvist J, et al. High prevalence of ischaemia, infection and serious comorbidity in patients with diabetic foot disease in Europe. Baseline results from the Eurodiale study. Diabetologia 2007;50:18.

7. Mutluoglu M, Sivrioglu AK, Eroglu M, et al. The implications of the presence of osteomyelitis on outcomes of infected diabetic foot wounds. Scand J Infect Dis 2013;45:497-503.

8. Falanga V. Wound healing and its impairment in the diabetic foot. Lancet 2005;366:1736-43.

9. Oliver RA, Lovric V, Yan Y, et al. Development of a novel model for the assessment of dead-space management in soft tissue. PLoS One 2015;10:e0136514. https://doi. org/10.1371/journal.pone.0136514

10. Agrawal A, Ayantunde AA, Cheung KL, et al. Concepts of seroma formation and prevention in breast cancer surgery. ANZ J Surg 2006;76:1088-95.

11. Chen CF, Lin SF, Hung CF, et al. Risk of infection is associated more with drain duration than daily drainage volume in prosthesis-based breast reconstruction: a cohort study. Medicine (Baltimore) 2016 Dec;95:e5605. DOI: 10.1097/ MD.0000000000005605

12. Ouldamer L, Bonastre J, Brunet-Houdard S, et al. Dead space closure with quilting suture versus conventional closure with drainage for the prevention of seroma after mastectomy for breast cancer (QUISERMAS): protocol for a multicentre randomised controlled trial. BMJ Open 2016;6: e009903. doi:10.1136/bmjopen-2015-009903.

13. Saltz R, Sierra D, Feldman D, et al. Experimental and clinical applications of fibrin glue. Plast Reconstr Surg 1991;88: 1005-15. 
14. Sood A, Kotamarti VS, Therattil PJ, et al. Sclerotherapy for the management of seromas: a systematic review. Eplasty 2017; 17:e25.
15. Morris AM. A controlled trial of closed wound suction. $\mathrm{Br} \mathrm{J}$ Surg 1973;60:357-9. 